\title{
Simultaneous Determination of Sunset Yellow and Carmoisine in Orange Flavored Soft Drink Samples by High-Performance Liquid Chromatography
}

\author{
Newsha Mahmoodi ${ }^{1}$, Mohammad Faraji $^{2, *}$, Parisa ziarati ${ }^{3}$ \\ ${ }^{1}$ Department of Food Science and Technology, Faculty of Science and innovative technology, Islamic Azad \\ University of Pharmaceutical Sciences, Tehran, Iran) \\ ${ }^{21}$ Faculty of Food Industry and Agriculture, Department of Food science \& Technology, Standard Research \\ Institute (SRI), Karaj P.O. Box 31745-139, Iran) \\ ${ }^{3}$ Department of Medicinal Chemistry, Faculty of Pharmacy, Pharmaceutical Sciences Branch, Islamic Azad \\ University, Tehran - Iran (IAUPS)
}

\begin{abstract}
An efficient method was developed for the simultaneous determination of sunset yellow and carmoisine in soft drink samples by high performance liquid chromatography (HPLC-UV-Vis). Affecting parameters on separation and detection of the dyes were investigated and optimized. Mixture of acetate buffer $p H=6.7$ and acetonitrile with ratio $78: 22$ as mobile phase; flow rate $1.0 \mathrm{ml} / \mathrm{min}$ and detection wavelength of $500 \mathrm{~nm}$ were selected as optimum values. For these dyes good linearity $\left(0.25-50 \mathrm{mg} \mathrm{L^{-1 }},>r^{2}=0.99\right)$ were obtained. Limits of detection for both of the dyes were $0.1 \mathrm{mg} \mathrm{L}^{-1}$. The recoveries of the dyes ranged from 90.4 to $109.2 \%$. Intra and inter-day precision expressed as relative standard deviation (RSD\%) at 5.0 and $50 \mathrm{mg} \mathrm{L} \mathrm{L}^{-1}$ levels less than $8.0 \%$ were also achieved. This method has been applied successfully in the determination of the dyes in soft drink samples. Sunset yellow and carmoisine were found in the samples in the range of 10.3-42.1 and N.D-4.5 mg $L^{-1}$, respectively. Obtained results showed that levels of the sunset yellow individually or in combination with carmoisine in all of the tested samples is lower than EU maximum permitted level $\left(100 \mathrm{mg}^{-1}\right)$. Keywords: Synthetic dyes, HPLC-UV/Vis, Sunset yellow, Carmoisine, Orange flavored soft drinks.
\end{abstract}

\section{Introduction}

Carbonated soft drinks are very popular beverages. Although their regular intake has been associated with human health problems [1-3]. carbonated soft drinks remain one of the most frequently consumed ready-todrink beverages in the world. They present particular characteristics such as high sugar content and acidity, and are available on the market in several flavors. In Iran, the most popular carbonated soft drinks are orange or cola-based.

Synthetic dyes are usually added to foodstuffs and soft drinks not only to improve appearance, colour and texture but also to maintain the natural colour during process or storage [4]. Compared to natural dyes, synthetic dyes show several advantages such as high stability to light, oxygen and $\mathrm{pH}$, colour uniformity, low microbiological contamination, relatively lower production costs, etc [5] .

Sunset yellow (SY, E-110) and carmoisine (E-122) are two highly used synthetic dyes which are added to many food products [6]. The presence and content of these dyes must be controlled due to their potential harmfulness to human beings [7].

An extensive review on the genotoxicity of food, drug, and cosmetic azo dyes and other dyes had been presented in the literature [8]. The European Union [9] has issued comprehensive schemes that regulating the use of food colours and their allowed levels in all food products. The maximum level of SY, and carmoisine dyes should not be more than $100 \mathrm{mg} \mathrm{L}^{-1}$ (individually or in combination) in nonalcoholic beverages with added juices and/or flavours [6]. Accordingly, monitoring of synthetic food dyes in high consumption products such as beverages becomes an essential task. Thus, it is necessary to develop accurate and reliable analytical methods for the confirmative determination of synthetic food dyes in soft drinks to ensure food safety and consumer health.

A large number of analytical methods for food colors have been proposed, such as thin layer chromatography (TLC) [10], voltammetry [11], polarography [12], spectrophotometry [13,14], capillary electrophoresis (CE) [15,16], ion chromatography [17], and high-performance liquid chromatography (HPLC) [18-24]. Voltammetry, polarography, and spectrophotometry are simple and rapid methods, however, they are not suitable for determining multiple food color mixtures in the food matrix. Therefore, HPLC is extensively used for determination of multiple food color mixtures in the food matrix.

Usually in formulation of orange flavored soft drinks sunset yellow is used but in some formulation combination of sunset yellow and carmoisine is also used in order to increase intensity of orange color. 
Therefore, the aim of this study was to develop and validate a fast, reliable, selective and economic HPLC method for routine analysis of sunset yellow and carmoisine dyes in orange flavored soft drinks samples in food analysis laboratories.

\subsection{Chemicals and Reagents}

\section{Experimental}

HPLC-grade methanol was obtained from Merck Company (Darmstadt, Germany). Analytical grade ammonium acetate and acetic acid were purchased from Merck Company (Darmstadt, Germany). Water was purified using a Milli-Q Ultrapure water purification system (Millipore, Bedford, MA, USA). Carmoisine and Sunset Yellow FCF (SY) were purchased from Sigma-aldrich (Steinheim, Germany).The structures, names and color index (C.I.) numbers of the dyes used in this study are shown in Fig. 1. All of the stock solutions (1000 mg $\left.\mathrm{L}^{-1}\right)$ were prepared in water. Working solutions $\left(20 \mathrm{mg} \mathrm{L}^{-1}\right)$ were prepared freshly mixing the stock solutions and diluting with water. Ammonium acetate buffer $\mathrm{pH}=6.7$ with concentration of $100 \mathrm{mM}$ was prepared by dissolving proper amount of salt in deionzed water by adjusting with dropwise addition of acetic acid followed by filtration.<smiles>O=S(=O)(O[Na])c1ccc(N=Nc2c(O)ccc3cc(S(=O)(=O)O[Na])ccc23)cc1</smiles>

Fig. 1: Chemical structure, name, color index and Enumber of the dyes used.

\subsection{Apparatus}

The chromatographic analysis was carried out in a high-performance liquid chromatography from Knauer of Germany model EuroChrom consisting of a degasser, quaternary pump (model K1100), manual sample injector with $20 \mu \mathrm{L}$ loop size and UV detector (model K2600) was controlled by EZChrom software. The HPLC operating mode was gradient, the injection volume was $20 \mu \mathrm{L}$ and the column temperature was adjusted at room temperature. The chromatography column was a Supelcosil LC-18: $25 \mathrm{~cm} \times 4.6 \mathrm{~mm}, 5 \mu \mathrm{m}$ (Supelco, Bellefonte, PA, USA). Sample data collection was optimized to 8 min per sample with UV detection at wavelength of $500 \mathrm{~nm}$. Mobile phase used was combination of methanol and ammonium acetate buffer (100 $\mathrm{mM}) \mathrm{pH}=6.7(22: 78, \mathrm{v} / \mathrm{v} \%)$ in isocratic mode. The mobile phase was filtered through a $0.45 \mu \mathrm{m}$ pore size filter (Merck Millipore, Billerica, Massachusetts, USA) and degassed by vacuum prior to use. Moreover, the mobile phase flow rate was set to $1.0 \mathrm{mLmin}^{-1}$. All of the $\mathrm{pH}$ measurements were performed with a WTW Inolab $\mathrm{pH}$ meter (Weilheim, Germany).

\section{Results and Discussion}

\subsection{Choosing the best Conditions for Detection and Separation of the Dyes}

It is well known that the detection wavelength is one of the most important factors affecting the sensitivity of the method. So, in order to achieve the highest sensitivity in determination of the dyes, the detection of them must be done in their $\lambda_{\max } \cdot \lambda_{\max }$ for SY and carmoisine is reported $485 \mathrm{~nm}$ and $515 \mathrm{~nm}$, respectively. So, detection wavelength was evaluated in the rage of 485-515 nm. Results showed that detection sensitivity is good for SY when $\lambda<500 \mathrm{~nm}$ specially $485 \mathrm{~nm}\left(\lambda_{\max }\right)$. On the other hand, detection sensitivity is good for carmoisine when $\lambda>500 \mathrm{~nm}$ specially $515 \mathrm{~nm}\left(\lambda_{\max }\right)$. So, under this circumstance, detection wavelength of $500 \mathrm{~nm}$ was selected in order to obtain good sensitivity for both of the dyes.

Composition of mobile phase is key factor in resolution of chromatographic separation as same as run time of analysis. Mobile phases containing ammonium acetate buffer as buffering compounds are obviously recommended as the most suitable to assure the very good chromatographic separation of the sulphonated azo dyes [23]. Several different mobile phases were tested including methanol-acetate buffer(15:85), methanolacetate buffer (20:80), methanol-acetate buffer (22:78), methanol-acetate buffer (25:75), methanol-acetate buffer (30:70). Obtained results showed that in low percent of methanol (methanol-acetate buffer (15:85)), carmoisine was eluted so late. On the other hand, in high percent of methanol (such as methanol-acetate buffer (30:70)), resolution of SY and carmoisine are not good. So, by evaluating these results, the mobile phase of methanol-acetate buffer (22:78) was selected because of suitable resolution, good peak shape and also short run 
time (10.0 min).Under optimum condition, the retention times for SY (first peak) and carmoisine (second peak) are about 3.5 and $8.5 \mathrm{~min}$, respectively.

\subsection{Analytical performance}

\subsubsection{Linear range}

The linearity for each compound was checked by analyzing mixed standard solutions of 8 different concentrations $\left(1,2,5,10,20,30,40\right.$, and $\left.50 \mathrm{mg} \mathrm{L}^{-1}\right)$. Table 1 shows the linear range found for each dyes and the regression coefficient obtained, expressed as $\mathrm{r}^{2}$.As can be seen, a wide and convenient linear range was obtained for the dyes.

\subsubsection{Precision}

The method exhibited excellent precision, as shown in Table 1. Fortification/recovery experiments resulted in low intra day relative standard deviations (R.S.D.s) for all analytes ( $\mathrm{n}=6$, R.S.D.s < 10\%). A comparison of fortification/recovery experiments conducted on six different days $(n=6)$ also displayed low inter-day R.S.D.s $(<9 \%)$, confirming the excellent reproducibility of the method.

Table 1. Analytical characteristics of the HPLC method

\begin{tabular}{|c|c|c|c|c|c|c|c|c|}
\hline \multirow[t]{3}{*}{ Dyes } & \multicolumn{4}{|l|}{ RSD $\%$} & \multirow{3}{*}{$\begin{array}{l}\text { LOQ } \\
(\mathrm{mg} / \mathrm{L})\end{array}$} & \multirow{3}{*}{$\begin{array}{l}\text { LOD } \\
(\mathrm{mg} / \mathrm{L})\end{array}$} & \multirow{3}{*}{$\begin{array}{l}\text { Linear Range } \\
(\mathrm{mg} / \mathrm{L})\end{array}$} & \multirow[t]{3}{*}{$\mathbf{R}^{2}$} \\
\hline & \multicolumn{2}{|c|}{ Inter-days $(n=6)$} & \multicolumn{2}{|c|}{ Intra-day $(n=6)$} & & & & \\
\hline & $5.0(\mathrm{mg} / \mathrm{L})$ & $\begin{array}{l}50.0 \\
(\mathrm{mg} / \mathrm{L})\end{array}$ & $\begin{array}{l}5.0 \\
(\mathrm{mg} / \mathrm{L})\end{array}$ & $\begin{array}{l}50 \\
(\mathrm{mg} / \mathrm{L})\end{array}$ & & & & \\
\hline Carmoisine & 6.8 & 4.7 & 5.2 & 3.5 & 0.25 & 0.1 & $0.25-50$ & 0.997 \\
\hline
\end{tabular}

\subsubsection{Detection and quantitation limits}

Detection limits were calculated by extracting diluted solutions of the analytes $(0.01,0.05,0.1$ and 0.2 $\left.\mathrm{mg} \mathrm{L}^{-1}\right)$. The criteria were selected according to IUPAC and ACS definition, as follows:

Detection limit (DL): $A_{s}-A_{b}=3 S_{b}$

Quantitation limit (QL): $A_{s}-A_{b}=10 S_{b}$

were $A_{s}$ is the average of sample signal (area); $A_{b}$ is the average of blank signal (area) and $S$ is the standard deviation of blank signal (area). The obtained limitsof the method are presented in Table 1.

\subsubsection{Accuracy}

Due to the lack of Certified Reference Materials, accuracy evaluation, in terms of percentage of recovery, was carried out on blank samples spiked with a known amount of analyte (level of $10 \mathrm{mg} \mathrm{L}^{-1}$ ). Data for these experiments are shown in Table 2. Good results were obtained, with average recoveries ranging from 92.2 to $101.4 \%$ and also between 92.7 and 98 for sunset yellow and carmoisine, respectively. It is interesting to note that, samples did not require matrix matched calibration curves to compensate for difficulties in measuring peak area for the dyes at low concentration, making more rapid analysis possible.

Table 2. Results of food color recovery study of the HPLC method

\begin{tabular}{|c|c|c|c|c|c|}
\hline \multirow[t]{2}{*}{ Sample } & \multirow[t]{2}{*}{$\mathrm{C}_{\text {added }}\left(\mathrm{mg} \mathrm{L}^{-1}\right)$} & \multicolumn{2}{|l|}{ Sunset yellow } & \multicolumn{2}{|l|}{ Carmoisine } \\
\hline & & $\mathrm{C}_{\text {found }}\left(\mathrm{mg} \mathrm{L}^{-1}\right)^{\mathrm{a}}$ & Recovery \% & $\mathrm{C}_{\text {found }}\left(\mathrm{mg} \mathrm{L}^{-1}\right)$ & Recovery \% \\
\hline \multirow[t]{2}{*}{ Soft drink 1} & - & 24.8 & - & 2.3 & - \\
\hline & 10.0 & 35.3 & 101.4 & 11.4 & 92.7 \\
\hline \multirow[t]{2}{*}{ Soft drink2 } & - & 37.5 & - & N.D & - \\
\hline & 10.0 & 45.3 & 95.4 & 9.6 & 96.0 \\
\hline \multirow[t]{2}{*}{ Soft drink3 } & - & 19.0 & - & 1.5 & - \\
\hline & 10.0 & 22.7 & 92.2 & 10.8 & 93.9 \\
\hline \multirow[t]{2}{*}{ Soft drink4 } & - & 42.1 & - & N.D & - \\
\hline & 10.0 & 50.2 & 96.4 & 9.8 & 98.0 \\
\hline \multirow[t]{2}{*}{ Soft drink5 } & - & 11.8 & - & 4.5 & - \\
\hline & 10.0 & 20.9 & 95.9 & 14.2 & 97.9 \\
\hline
\end{tabular}

${ }^{a}$ RSD values for three replicate measurements for all of the tested samples were less than $10 \%$

\subsection{Application}

The validated method was applied to determine content of sunset yellow and carmoisine in different soft drink samples collected locally and the results are summarized in Table 3. RSD values for three replicate measurements for all of the tested samples were less than $7.0 \%$. In the analysis of the samples, peak identification was based on the comparison between the retention times of standard compounds and was confirmed by spiking standards to the samples. Quantification was based on the external standard method using calibration curves fitted by linear regression analysis. Under the stated experimental conditions, baseline 
separation of the two dyes was achieved in less than 10 min. A typical HPLC-UV-Vischromatogram of acarbonated soft drink sample is shown in Figure. 2.

The average sunset yellow concentration of the 20 soft drink samples range between $10.3-49.4 \mathrm{mg} \mathrm{L}^{-1}$. Also, carmoisine was found in the soft drink samples in the range of N.D-4.5 mg L ${ }^{-1}$. There results confirmed that there are two different formulations in soft drink sample samples. In some samples only sunset yellow has been used to produce orange color but some companies has been used combination of the both sunset yellow and carmoisine in their formulation. Moreover, sum of the sunset yellow and carmoisine concentration in the tested soft drink sample are in compliance with EU limit $\left(100 \mathrm{mg} \mathrm{L}^{-1}\right)$.

Table 3. Concentration of the food colorants in the samples

\begin{tabular}{|c|c|c|c|}
\hline Sample & Sunset yellow $\left(\mathrm{mg} \mathrm{Kg}^{-1}\right)$ & Carmoisine $\left(\mathrm{mg} \mathrm{Kg}^{-1}\right)$ & Sample compliance with EU limit $\left(100 \mathrm{mg} \mathrm{L}^{-1}\right)$ \\
\hline Soft drink 1 & 24.8 & 2.3 & No \\
\hline Soft drink 2 & 14.7 & 1.3 & No \\
\hline Soft drink 3 & 20.9 & 1.9 & No \\
\hline Soft drink 4 & 10.3 & N.D & No \\
\hline Soft drink 5 & 19.6 & 1.5 & No \\
\hline Soft drink 6 & 12.1 & 1.5 & No \\
\hline Soft drink 7 & 11.8 & 3.6 & Yes \\
\hline Soft drink 8 & 37.5 & N.D & No \\
\hline Soft drink 9 & 14.1 & 1.0 & - \\
\hline Soft drink 10 & 13.0 & N.D & No \\
\hline Soft drink 11 & 21.4 & 1.3 & No \\
\hline Soft drink 12 & 42.1 & N.D & No \\
\hline Soft drink 13 & 19.0 & 1.5 & - \\
\hline Soft drink 14 & 18.2 & 1.3 & No \\
\hline Soft drink 15 & 27.7 & 1.7 & No \\
\hline Soft drink 16 & 22.8 & N.D & No \\
\hline Soft drink 17 & 49.4 & N.D & - \\
\hline Soft drink 18 & 8.4 & N.D & No \\
\hline Soft drink 19 & 16.0 & N.D & - \\
\hline Soft drink 20 & 11.8 & 4.5 & No \\
\hline
\end{tabular}

${ }^{\text {a }}$ samples with natural color
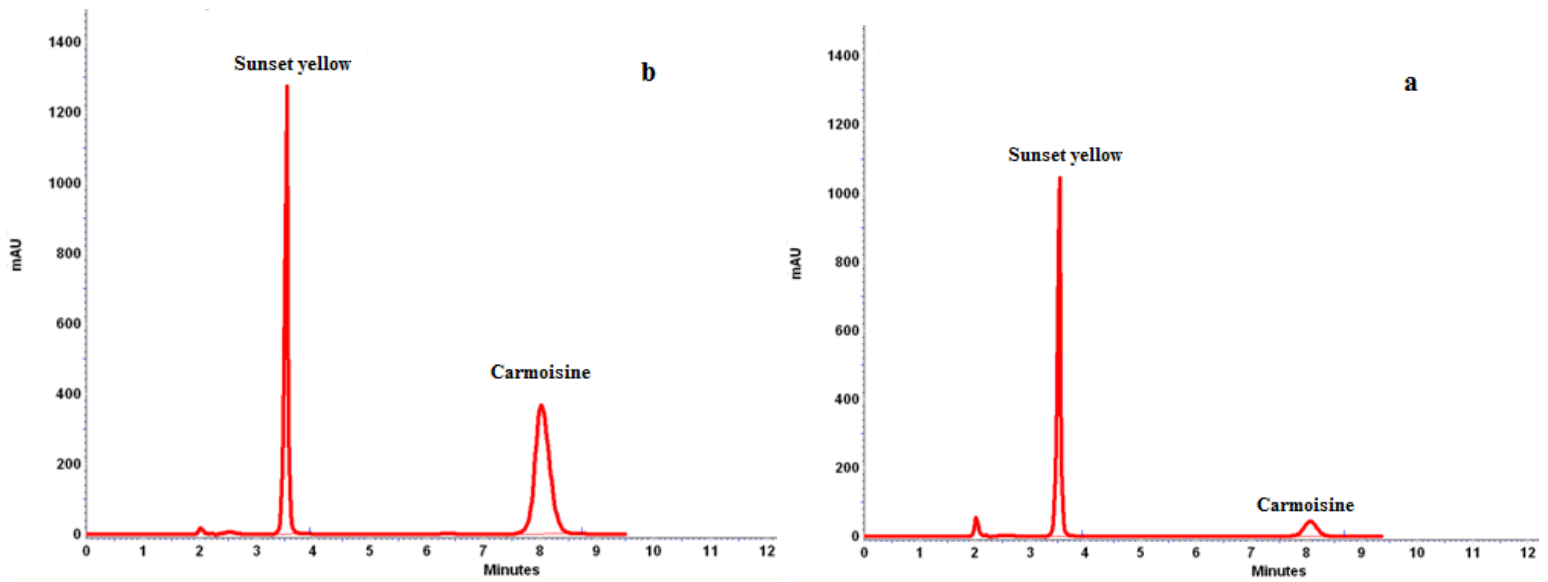

Fig. 2. HPLC-UV-vis chromatogram $(\lambda=500 \mathrm{~nm})$ sample of soft drink 15 (a) nonspiked and (b) spike of $10 \mathrm{mg}$ $\mathrm{L}^{-1}$ of mixture standard solution of the two dyes

\section{Conclusion}

Due to the lack of International Standard Method for the determination of the synthetic dyes in foodstuff, in this research we propose an analytical method for the simultaneous determination of the sunset yellow and carmoisine in different soft drink samples. Proposed method is simple, sensitive, rapid, reliable and allows good recoveries of the sunset yellow and carmoisine in the tested samples. Analysis of the samples showed that some samples only have sunset yellow. In contrast, some companies are used combination of the both sunset yellow and carmoisine in their formulation. Moreover, sum of the sunset yellow and carmoisine concentration in the tested soft drink sample are in compliance with EU limit $\left(100 \mathrm{mg} \mathrm{L}^{-1}\right)$. 


\section{References}

[1]. R.P. Heaney and K. Rafferty, Carbonated beverages and urinary calcium excretion. American Journal of Clinical Nutrition, 74, 2001, 343-347.

[2]. V.S. Malik, M.B. Schulze and F.B. Hu, Intake of sugar-sweetened beverages and weight gain: A systematic review. American Journal of Clinical Nutrition, 84, 2006, 274-278.

[3]. G. Wyshak, R.E. Frisch, T.E. Albright, N.L. Albright, I. Schiff and J. Witschi, Nonalcoholic carbonated beverage consumption and bone fractures among women former college athletes. Journal of Orthopaedic Research, 7, 1989, 91-99.

[4]. S.P. Alves, D. Mares Brum, E.C. Branco de Andrade and A.D.P. Netto, Determination of synthetic dyes in selected foodstuffs by high performance liquid chromatography with UV-DAD detection. Food Chemistry, 107, 2008, 489-496.

[5]. N.E. Llamas, M. Garrido, M.S. Di Nezio and B.S. Fernandez, Band Second order advantage in the determination of amaranth, Sunset yellow FCF and Tartrazine by UV-vis and multivariate curve resolution-alternating least squares. Analytica Chimica Acta, $655,2009,38-42$.

[6]. Y.S. Al-Degs, Determination of three dyes in commercial soft drinks using HLA/GO and liquid chromatography. Food Chemistry, 117, 2009, 485-490.

[7]. W. Zhang, T. Liu, X. Zheng, W. Huang and C. Wan, Surface-enhanced oxidation and detection of Sunset yellow and Tartrazine using multi-walled carbon nanotubes film-modified electrode. Colloids and Surface B, 74, 2009, $28-31$.

[8]. R.D. Combes and R.B. Haveland-Smith, A review of the genotoxicity of food, drug and cosmetic colours and other azo, triphenylmethane and xanthene dyes. Mutation Research: Reviews in Genetic Toxicology, 98, 1982, 101-243.

[9]. Directive 94/36//EC on colours for use in foodstuffs (1994). European Parliament and Council.

[10]. H. Oka, Y. Ikai, N. Kawamura, M. Yamada, H. Inoue, T. Ohno, K. Inagaki, A. Kuno and N. Yamamoto, Simple method for the analysis of food dyes on reversed-phase thin-layer plates. Journal of Chromatography, 411, 1987, 437-44.

[11]. Y. Ni, J. Bai and L. Jin, Simultaneous adsorptive voltammetric analysis of mixed colorants by multivariate calibration approach. Analytica Chimica Acta 329, 1996, 65-72.

[12]. S. Combeau, M. Chatelut and O. Vittori, Identification and simultaneous determination of Azorubin, Allura red and Ponceau 4R by differential pulse polarography: application to soft drinks. Talanta, 56, 2002, 115-122.

[13]. J.J.B. Nevado, J.R. Flores, M.J.V. Llerena and N.R. Farinas, Rapid spectrophotometric method to resolve ternary mixtures of Tartrazine, Quinoline Yellow and Patent Blue V in commercial products, Fresenius Journal of Analytical Chemistry, 365, 1999, 383-388.

[14]. E.C. Vidotti, J.C. Cancino, C.C. Oliveira and M.D.C.E. Rollemberg, Simultaneous determination of food dyes by first derivative spectrophotometry with sorption onto polyurethane foam. Analytical Science, 21,2005, 149-153.

[15]. H.Y. Huang, Y.C. Shih and Y.C. Chen, Determining eight colorants in milk beverages by capillary electrophoresis, Journal of Chromatography A, 959, 2002, 317-325.

[16]. M.A. Prado, L.F.V. Boas, M.R. Bronze and H.T. Godoy, Validation of methodology for simultaneous determination of synthetic dyes in alcoholic beverages by capillary electrophoresis. Journal of Chromatography A, 1136, 2006, 231-236.

[17]. Q.C. Chen, S.F. Mou, X.P. Hou, J.M. Riviello and Z.M. Ni, Determination of eight synthetic food colorants in drinks by highperformance ion chromatography, Journal of Chromatography A, 827, 1998, 73-81.

[18]. K. Nakazawa, Y. Shimamura, K. Nakajima, Y. Kikuchi, K. Nakagome and Y. Tamura, Studies on Newer Adulterants and Contaminants. Annual Report of The Tokyo Metropolitan Research Laboratory of Public Health, 46, 1995, $108-114$.

[19]. T. Zou, P. He, A. Yasen, Z. Li, Determination of seven synthetic dyes in animal feeds and meat by high performance liquid chromatography with diode array and tandem mass detectors. Food Chemistry, 138, 2013, 1742-1748.

[20]. J. Kirschbaum, C. Krause, S. Pfalzgraf and H. Bruckner, Development and evaluation of an HPLC-DAD method for determination of synthetic food colorants. Chromatographia, 57, 2003, S115-S119.

[21]. M.G. Kiseleva, V.V. Pimenova and K.I. Eller, Determination of Synthetic Dyes in Food. Journal of analytical Chemistry, 58, 2003, 685-690.

[22]. M.S. Garcia-Falcon and J. Simal-Gandara, Determination of food dyes in soft drinks containing natural pigments by liquid chromatography with minimal clean-up. Food Control, 16, 2005, 293-297.

[23]. K.S. Minioti, C.F. Sakellariou and N.S. Thomaidis, Determination of 13 synthetic food colorants in water-soluble foods by reversed-phase high-performance liquid chromatography coupled with diode-array detector, Analytica Chimica Acta, 583, 2007, 103-110.

[24]. N. Yoshioka and K. Ichihashi Determination of 40 synthetic food colors in drinks and candies by high-performance liquid chromatography using a short column with photodiode array detection. Talanta, 74, 2008, 1408-1413. 